\title{
Arteriovenous Fistula Involving Both Coronary Arteries and Main Pulmonary Trunk
}

\author{
L. HUMBLET, J. DELVIGNE, H. KULBERTUS^, P. COLLIGNON^, AND H. JORIS \\ From the Division of Cardiology, University Department of Internal Medicine, and the Department of Radiodiagnosis, \\ Hôpital de Bavière, Liège, Belgium
}

Anomalous communication between the coronary arterial tree and a cardiac chamber or great vessel was first described by Krause in 1865 . To date more than 100 cases have been reported. The earlier papers consisted of descriptions of necropsies but in the past few years, the introduction of heart catheterization, intracardiac phonocardiography, and angiocardiographic techniques has enhanced the interest in these anomalies. Several cases have been diagnosed during life and corrected by operation.

The purpose of this paper is to present a patient with an unusual form of coronary arteriovenous fistula : both coronary arteries gave rise to an anomalous branch opening into an aneurysmal mass which overlay the main pulmonary artery and communicated with it.

\section{Case Report}

A 47-year-old man, previously working as a coal-miner, was admitted in February 1966 for evaluation of a cardiac murmur which had been known for 21 years. He had been entirely asymptomatic throughout his life. On physical examination, the pulse rate was 70 a minute and the blood pressure $120 / 90 \mathrm{~mm}$. Hg. The arterial pulses were normal, with no sign of "run-off", and the jugular venous pressure was not raised. The first sound was soft and the second normally split. There was a continuous murmur best heard in the 2 nd left interspace and radiating widely over the praecordium. This murmur was sharply diminished during the strain and early post-strain period of a Valsalva manoeuvre.

The electrocardiogram showed a sinus rhythm and a slight delay in right ventricular excitation.

The chest $x$-ray showed anthracosilicosis grade p2 (International Labour Office, 1959). The left ventricle

* Aspirants du Fond National Belge de la Recherche Scientifique. was mildly enlarged and the ascending aorta appeared unfolded and dilated. There was no sign of pulmonary hyperaemia.

The phonocardiogram confirmed the presence of a continuous murmur best recorded in the 2 nd left interspace. The greatest amplitude was in late systole and early diastole. There was no gap between the systolic and diastolic phases of the murmur which rode over the second sound without interruption.

At right heart catherization, the pressures were normal in the cardiac chambers, pulmonary artery, and wedge position. A significant increase in oxygen saturation (7\%) was disclosed at pulmonary artery level. The leftto-right shunt was $1.411 . / \mathrm{min} . / \mathrm{m}^{2}{ }^{2}$, i.e. 40 per cent of the systemic output.

Intracardiac phonocardiography, using an Allard-Laurens' micromanometer, showed a continuous murmur present only in a very limited area, 2 to $3 \mathrm{~cm}$. above the pulmonary valve. The greatest intensity was recorded when the side-hole of the catheter was on or just below the valvular level. The murmur disappeared when the catheter was pulled back into the right ventricle or pushed further into the pulmonary artery.

Retrograde aortography (Fig.) from the left femoral artery showed a moderate unfolding and dilatation of the ascending aorta. The coronary arteries were in normal position but grossly dilated. They each gave rise to a large anomalous branch which entered a cirsoid formation overlying the usual site of the pulmonary artery. The contrast medium slowly disappeared from this mass, and in the late films venous drainage from the aneurysm became visible. Logetronic printing showed in the antero-posterior view a slight opacification of the pulmonary artery. In the lateral films, it seemed that the more important contribution to the fistula was provided by the right coronary artery.

A diagnosis of arteriovenous fistula between the coronary arteries and the pulmonary trunk was made. 

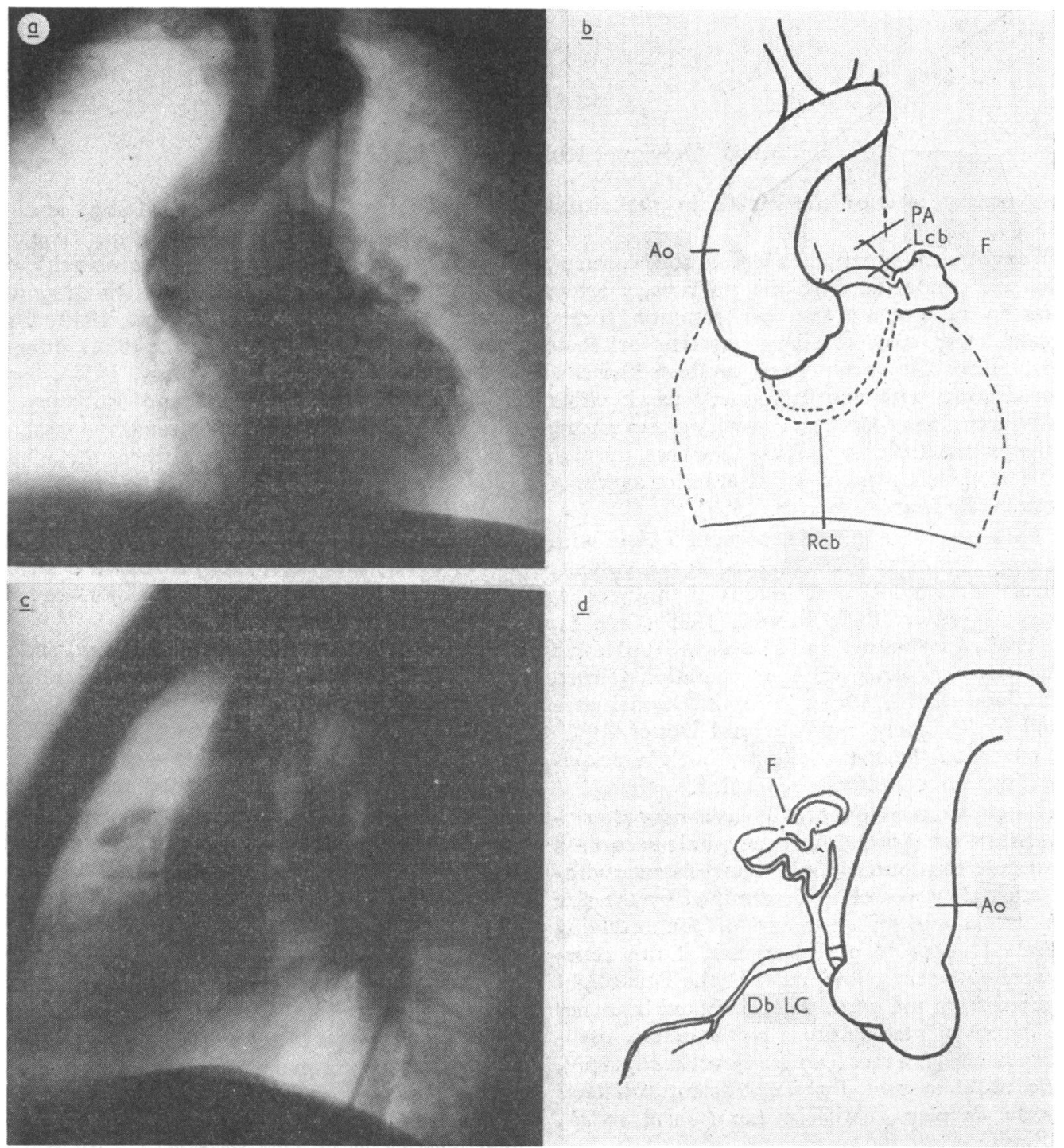

Fig.-Retrograde aortography (see text for description). (a) and (b): antero-posterior view; (c) and (d): left lateral view. Ao, aorta; PA, pulmonary artery; Lcb, branch from the left coronary artery; Rcb, branch from the right coronary artery; F, aneurysm with fistula; Db LC, descending branch of the left coronary.

In view of the small shunt, absence of symptoms, and relative rarity of the reported complications, neither operation nor treatment seemed necessary.

\section{Discussion}

There are two main types of communication between the coronary arterial tree and a cardiac chamber or great vessel (Edwards, 1958; Gasul et al., 1960): those that communicate with the right side of the circulation (right atrium and its tributaries, 9* right ventricle, or pulmonary artery) causing a leftto-right shunt; and those that communicate with the left atrium or left ventricle causing an arterial runoff. The former are more frequent and the communication is usually with the right atrium $(40 \%)$, the right ventricle $(40 \%)$, or the main pulmonary trunk (20\%) (Gasul et al., 1960; Upshaw, 1962; Soulié et al., 1963; Currarino, Silverman, and Landing, 1959). The right coronary is involved twice as frequently as the left but, in some cases, 
both coronary arteries participate in the fistula (10-15\%).

The anatomical situation in which both coronary arteries are connected with the pulmonary artery appears to be one of the less common forms. Generally, the two coronary arteries originate normally from the aorta. They produce branches communicating with the pulmonary trunk either directly through an accessory coronary artery arising from the pulmonary artery, or, as in our case, through a plexus of vessels situated at the anterior aspect of the base of the heart (Edwards, 1958).

We have been able to find reports of 5 cases with an anomaly similar to that disclosed in our patient: 4 of them consisted of descriptions of the heart at necropsy (Krause, 1865; Brooks, 1885 (Case 1); Scott, 1948; Carmichael and Davidson, 1961), and the last one was discovered at operation (Ernst, Klassen, and Ryan, 1961). An additional case reported by Steinberg, Baldwin, and Dotter (1958) might have had the same anatomy but the vessels involved were not positively identified.

The functional consequences of a coronary arteriovenous fistula are those of any congenital or acquired arteriovenous communication. The resistance within the anomalous vessels is determined by the size of the fistula and the pressure of the receiving chamber. One could postulate that, if this resistance were sufficiently low, most of the flow might be diverted from the normally distributed branches of the coronary vasculature. Nevertheless, myocardial ischaemia is a rare feature (Gasul et al., 1960), and one could assume that an efficient collateral circulation develops early in life (Gasul et al., 1960; Soulié et al., 1963).

One of the most striking features on physical examination is the cardiac murmur, which is nearly always continuous; its location and loudness vary according to the site of the receiving chamber (Gasul et al., 1960).

The chest radiographs are not different from those in any other left-to-right shunt. However, dilatation and unfolding of the ascending aorta, which was present in our case, has sometimes been reported even in very young patients (Gasul et. al., 1960). Calcifications within the fistula were also noted in rare instances (Colbeck and Shaw, 1954).

Cardiac catheterization and intracardiac phonocardiography can localize and quantify the shunt. The all important definition of the anatomy and exclusion of a patent ductus arteriosus, ventricular septal defect with aortic incompetence, ruptured sinus of Valsalva, aortico-left ventricular tunnel, aortico-pulmonary septal defect, and arteriovenous fistula in the lungs or chest wall, can only be settled by aortography (Edwards, Gladding, and Weir, 1958; Gasul et al., 1960; Soulié et al., 1963).

The prognosis depends on the severity of the shunt and on certain complications which sometimes occur, such as heart failure (Scott, 1948; Colbeck and Shaw, 1954; Steinberg et al., 1958), pulmonary hypertension (Neill and Mounsey, 1958), bacterial endarteritis (Sanger, Taylor, and Robicsek, 1959; Michaud et al., 1963), coronary insufficiency (Edwards et al., 1958), and rupture of the aneurysm (Habermann, Howard, and Johnson, 1963).

In the past few years, surgical closure of the fistula has been achieved in several patients (Gasul et al., 1960; Cooley and Ellis, 1962; Michaud et al., 1963; Sabiston, 1963; Soulié et al., 1963; Björk and Björk, 1965).

The operative risks are said to be low, and some authors think that an operation should be undertaken in practically all proven cases (Gasul et al., 1960). Nevertheless, operative deaths (Cooley and Ellis, 1962; Michaud et al., 1963) as well as myocardial infarction after operation (Cooley and Ellis, 1962; Michaud et al., 1963) have been reported.

Therefore, in view of its good prognosis and the rarity of complications, we agree with Cooley and Ellis (1962), Soulié et al. (1963), and Nadas (1963) that there is no need for an operation when the shunt is trivial.

\section{Summary}

We report a case of coronary arteriovenous fistula in which both coronary arteries are connected via a cirsoid aneurysm with the pulmonary trunk. The discovery of a cardiac murmur in a middle-aged man without symptoms prompted a physiological investigation in which right heart catheterization, intracardiac phonocardiography, and retrograde aortography were used to demonstrate and evaluate the anomaly. Previously reported instances of this condition and the indications for operation are briefly discussed.

\section{References}

Björk, V. O., and Björk, L. (1965). Coronary artery fistula. 7. thorac. cardiovasc. Surg., 49, 921.

Brooks, H. St. J. (1885). Two cases of an abnormal coronary artery of the heart arising from the pulmonary artery: with some remarks upon the effect of this anomaly in producing cirsoid dilatation of the vessels. f. Anat. (Lond.), 20, 26.

Carmichael, D. B., and Davidson, D. G. (1961). Congenital coronary arteriovenous fistula. Amer. F. Cardiol., 8, 846.

Colbeck, J. C., and Shaw, J. M. (1954). Coronary aneurysm with arteriovenous fistula. Amer. Heart f., 48, 270.

Cooley, D. A., and Ellis, P. R. (1962). Surgical considerations of coronary arteriovenous fistula. Amer. $\mathcal{F}$. Cardiol., 10, 467. 
Currarino, G., Silverman, F. N., and Landing B. H. (1959). Abnormal congenital fistulous communications of the coronary arteries. Amer. F. Roentgenol., 82, 392.

Edwards, J. E. (1958). Editorial: Anomalous coronary arteries with special reference to arteriovenous-like communications. Circulation, 17, 1001.

—- Gladding, T. C., and Weir, A. B. (1958). Congenital communication between the right coronary artery and the right atrium. F. thorac. Surg., 35, 662.

Ernst, C. B., Klassen, K. P., and Ryan, J. M. (1961). Vascular malformation overlying the pulmonary artery simulating a patent ductus arteriosus. Circulation, 23, 759.

Gasul, B. M., Arcilla, R. A., Fell, E. H., Lynfield, J., Bicoff, J. P., and Luan, L. L. (1960). Congenital coronary arteriovenous fistula. Clinical, phonocardiographic, angio-cardiographic and hemodynamic studies in five patients. Pediatrics, 25, 531.

Habermann, J. H., Howard, M. L., and Johnson, E. S. (1963). Rupture of the coronary sinus with hemopericardium. A rare complication of coronary arteriovenous fistula. Circulation, 28, 1143.

International Labour Office (1959). New International Classification of Radiographs of the Pneumoconioses. Geneva, 1958. Occup. Safety Hlth, 9, 63.

Krause, W. (1865). Ueber den Ursprung einer accessorischen
A. coronaria cordis aus der A. pulmonalis. Z. rationelle Med., 3rd ser., 24, 225.

Michaud, P., Froment, R., Viard, H., Gravier, J., and Verney, R. N. (1963). Les fistules coronaro-ventriculaires droites. Arch. Mal. Coeur, 56, 143.

Nadas A. S. (1963). Pediatric Cardiology, 2nd ed. W. B. Saunders, Philadelphia and London.

Neill, C., and Mounsey, P. (1958). Auscu'tation in patent ductus arteriosus with a description of two fistulae simulating patent ductus. Brit. Heart f., 20, 61.

Sabiston, D. C. (1963). Direct surgica'. management of congenital and acquired lesions of coronary circulation. Progr. cardiovasc. Dis., 6, 299.

Sanger, P. W., Taylor, F. H., and Robicsek, F. (1959). The diagnosis and treatment of coronary arteriovenous fistula. Surgery, 45, 344.

Scott, D. H. (1948). Aneurysm of the coronary arteries. Amer. Heart F., 36, 403.

Soulié, P., Mathey, J., Di Matteo, J., Vernant, P., Piton, A., Bouchard, F., and Neveux, J. Y. (1963). Communications congénitales entre artères coronaires et cavités cardiaques. Arch. Mal. Coeur, 56, 121.

Steinberg, I., Baldwin, J. S., and Dotter, C. T. (1958). Coronary arteriovenous fistula. Circulation, 17, 372.

Upshaw, C. B. (1962). Congenital coronary arteriovenous fistulas. Report of a case with an analysis of 73 reported cases. Amer. Heart f., 63, 399. 